\title{
ANÁLISE DA CORRELAÇÃO DA LUCRATIVIDADE COM OUTROS INDICADORES FINANCEIROS DE EMPRESAS DE VAREJO DE VESTUÁRIO E CALÇADOS LISTADAS NA BOVESPA
}

$\begin{array}{ll}\text { Nome } & \text { Celso Zanella } \\ \text { Instituição/Afiliação } & \text { IFRS Campus Farroupilha } \\ \text { País } & \text { Brasil } \\ \text { Nome } & \text { Delma Tânia Bertholdo } \\ \text { Instituição/Afiliação } & \text { IFRS Campus Farroupilha } \\ \text { País } & \text { Brasil } \\ & \\ \text { Nome } & \text { Leandro Lumbiere } \\ \text { Instituição/Afiliação } & \text { IFRS Campus Farroupilha } \\ \text { País } & \text { Brasil } \\ & \\ \text { Nome } & \text { Tânia Craco } \\ \text { Instituição/Afiliação } & \begin{array}{l}\text { IFRS Campus Farroupilha } \\ \text { País }\end{array} \\ \text { Brasil } \\ \text { País }\end{array}$

\section{RESUMO}

Este trabalho teve por objetivo elencar, dentro do setor das empresas do vestuário, as empresas com ações na Bolsa de Valores de São Paulo com sistema de governança corporativa novo mercado (NM). Para chegar a este objetivo, extraíram-se dos demonstrativos financeiros destas empresas dados para cálculo dos indicadores de liquidez corrente, giro do estoque, índice de endividamento geral, tamanho da empresa medido pelo ativo total e pelo faturamento e o índice de lucratividade. Através da correlação linear, calculada pelo software R Studio, verificou-se quais indicadores mais se correlacionam com o indicador de lucratividade. $\mathrm{O}$ indicador de lucratividade foi escolhido por ser essencial na análise da situação financeira das empresas. Após realizar a identificação dos indicadores e sua correlação com a lucratividade, constatou-se que dois deles, o giro do estoque e o tamanho da empresa, medido por dois indicadores, são os que possuem a maior correlação com o indicador de lucratividade.

Palavras-chave: varejo, indicadores, correlação, lucratividade. 


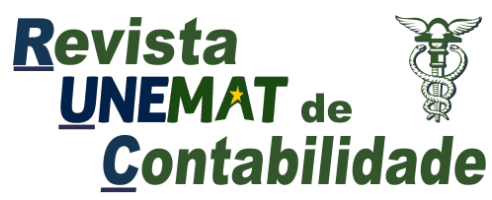

v. 9, n. 17,2020

\begin{abstract}
The clothing and footwear retail sector is very important in the national economy and creates thousands of jobs. This industry is very fragmented and has structural problems such as logistics and low operational efficiency. This paper aims to list companies with stock quotes on the São Paulo's Stock Exchange that uses the New Market system of corporate governance. Using the financial statement of the companies to extract data for calculating these indicators: current liquidity, inventory turnover, overall debt ratio, company size measured by the total assets and the revenues and profitability index. Through calculate the linear correlation, this work will find what or which indicators are more correlated with the profitability indicator. The profitability indicator was chosen because it is essential in the analysis of financial health of companies. After making the identification of indicators and their correlation with the profitability, it was found that two of them, the inventory turnover and company size, measured by two indicators, are those with the highest correlation with the profitability indicator.
\end{abstract}

Keywords: retail, indicators, correlation, profitability.

\title{
1 INTRODUÇÃO
}

O setor de varejo de vestuário e calçados tem grande relevância na economia brasileira. Foi responsável por mais de 3,1\% do PIB (Produto Interno Bruto) de serviços no Brasil em 2013, com faturamento de R 89 bilhões, segundo dados da Euromonitor. É um setor bastante fragmentado e as cinco principais redes de varejo são responsáveis por cerca de 17\% do setor. É dinâmico e vem crescendo, em média, $10 \%$ ao ano desde 2008.

Para Miriam Goldemberg (2006, p. 9), "a moda é hoje um dos temas mais fascinantes porque, por meio dela, podemos analisar inúmeros aspectos de uma cultura". É um sistema que acompanha o vestuário e o tempo, que integra o simples uso de roupas no dia-a-dia a um contexto maior: político, social, sociológico. Fator essencial à sobrevivência de qualquer empresa, a lucratividade é um dos principais indicadores da situação financeira de toda organização. Gitman (2010, p. 58) diz que "proprietários, credores e administradores dão muita atenção à expansão dos lucros por causa da grande importância que o mercado lhes atribui".

O site da B3, empresa que lista os ativos disponíveis para negócio, mostra um relatório onde é possível observar o aumento de 60\% no número de investidores de 2008 a 2019, passando de 530 para mais de 1 milhão de CPF's cadastrados.

Em países como o Brasil, o mercado de ações tem um papel importante para o crescimento da economia, auxiliando as empresas a crescerem cada vez mais e se desenvolverem, porém, ele necessita que pessoas tenham a educação e consciência de investir 


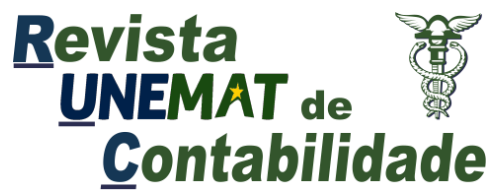

v. 9, n. 17,2020

seu dinheiro para uma garantia financeira futura, e também contribuírem para o desenvolvimento do país além do crescimento pessoal. Quando se compreende as vantagens tanto para a empresa e para a economia, quanto para as pessoas, o mercado de ações fica cada vez mais ativo, e contribui mais para o desenvolvimento econômico do país (RECH et al., 2019).

Listadas no índice Bovespa, no setor Consumo Cíclico - Vestuário e Calçados e participantes do sistema de governança corporativa Novo Mercado, as quatro empresas que serão analisadas neste trabalho são concorrentes no mercado em que atuam. $\mathrm{O}$ objetivo do estudo é identificar, dentre cinco variáveis selecionadas, qual a variável que está mais intimamente correlacionada com o indicador de lucratividade nas empresas listadas no índice Bovespa, no segmento Consumo Cíclico - Vestuário e Calçados participantes do Sistema de governança corporativa Novo Mercado nos anos de 2010 a 2014. Na medida em que as organizações precisam se tornar mais competitivas, em especial no segmento de varejo onde a disputa pelos clientes é acirrada, saber quais fatores influenciam mais diretamente a lucratividade, é essencial para, não só ser competitivo, mas aumentar a lucratividade, pois isso lhe permite dar uma resposta positiva ao mercado e aos seus stakeholders.

A questão de pesquisa que norteia o trabalho é: quais os indicadores financeiros melhor se correlacionam com a lucratividade que foi o indicar financeiro escolhido por retratar com mais confiabilidade a condição financeira das empresas?

\section{REFERENCIAL TEÓRICO}

O mercado de ações é uma ferramenta fundamental para o desenvolvimento econômico de um país, ele processa e distribui capitais para investimento, estimulando as atividades econômicas, além de permitir que toda a sociedade possa participar amplamente na riqueza e nos resultados da economia, além de contribui para uma melhor distribuição de renda, levando o dinheiro das poupanças mais para os investidores (OLIVERIA, 1980).

Gitman (2010) define o mercado de capitais como aquele que admite que ofertantes e demandantes realizem transações de fundos de longo prazo, no exemplo, emissões de títulos governamentais e também títulos de empresas. Dessa forma, para Hoji (2010), a finalidade do mercado de capitais é a de financiar as atividades produtivas e o capital de giro das empresas. Para isso, no Brasil, são utilizados três instrumentos principais, que são as ações, as 


\section{Revista \\ UNEMAT de \\ Contabilidade}

debêntures e as notas promissórias. Esse mercado é formado basicamente pelos sub mercados de corretagem e distribuição, onde são efetuadas transações com obrigações e ações.

Segundo Gitman (2010), o mercado de corretagem forma-se a partir bolsas de valores nacionais e regionais, no qual organizações oferecem um ambiente que possibilita às empresas levantarem fundos por meio da venda de novos títulos. A Bolsa de Valores de São Paulo é o principal mercado de negociação de ações de empresas de capital aberto do Brasil. No ano de 2008 integrou suas operações com a Bolsa Mercantil e de Futuros (BM\&F) formando a BM\&FBOVESPA. Segundo o sítio da BM\&FBOVESPA na internet, "é uma companhia que administra mercados organizados de títulos, valores mobiliários e contratos derivativos". Seu principal índice é o IBOVESPA e as principais empresas do país estão listadas no mercado de ações da BOVESPA.

O investimento na bolsa de valores é cercado de muitos mitos, mas também existem algumas verdades. Comparar a bolsa de valores a um cassino é um dos mitos mais comum, outro é de que este é um investimento apenas para quem tem muito dinheiro. Há quem diga que quem não suporta riscos não deva optar por esta aplicação (ELDER, 2017).

O investidor deve buscar negócios saudáveis e lucrativos, os números como na mais pura lógica da matemática não mentem, o grande diferencial do investidor bem-sucedido é saber analisar onde está aplicando os seus recurso e se é um lugar saudável e promissor, e não uma empresa falida e predadora de pequenos acionistas (GARCIA, 2017).

Assim com a onda Fintechs que praticamente zeraram as taxas para se ter uma conta em uma instituição financeira, e criaram facilidades para os usuários, as corretoras, que são, as empresas responsáveis por intermediar as transações entre o investidor e a bolsa de valores, estão em uma constante batalha para aumentarem sua base de clientes, isso faz com que cada dia os usuários tenham serviços a preços cada vez menores, não é incomum encontrar corretoras que não cobrem mais nenhuma taxa para investimento em no mercado de capitais (MALLMANN, 2017). A constante baixa nos custos, faz com que com apenas $\mathrm{R} \$ 100$, ou até menos, já seja possível investir em um ou mais ativos, dando oportunidade a iniciantes investirem somente uma pequena parte do seu capital no início da sua jornada de investidor (MALLMANN, 2017).

As empresas listadas no índice BOVESPA são obrigadas pela legislação a apresentar demonstrações financeiras trimestrais e balanços anuais para que os interessados possam analisá-los. Segundo Hoji, (2010), são cinco as principais demonstrações financeiras apresentadas aos acionistas: demonstração de resultado, balanço patrimonial, demonstração 


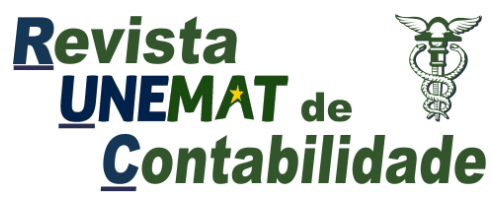

v. 9, n. 17,2020

das mutações do patrimônio líquido, demonstração dos fluxos de caixa e demonstração do valor adicionado. Dessas demonstrações, serão retirados índices financeiros para comparação e obtenção da correlação entre eles.

Gitman (2010) classifica os índices financeiros em cinco categorias principais: liquidez, atividade, endividamento, lucratividade e valor de mercado. Através deste trabalho procura-se entender a correlação entre o índice de lucratividade e os demais, excluído o de valor de mercado, nas empresas listadas no índice BOVESPA, presentes no setor de consumo cíclico-vestuário e calçados e participantes do sistema de governança corporativa Novo Mercado nos anos de 2010 a 2014. Serão incluídas mais duas variáveis independentes neste trabalho para medir sua correlação com a variável dependente lucratividade, que são as receitas financeiras e o tamanho da empresa medido de duas formas: pelo ativo total e pelo faturamento bruto.

Outra forma de avaliação de investimentos é pela análise técnica (gráfica) dos ativos. Os analistas desta escola não consideram o humor, medo, ganância, informações secretas, etc. Somente procuram conhecer e mensurar a Lei da Oferta e Procura. Através da análise dos preços de abertura e fechamento em um determinado tempo. Procuram identificar oportunidades de operações atraentes, otimizar as entradas e saídas de investimento do mercado. A partir da análise dos limites de oscilação nos preços procuram estabelecer estratégias de risco. A análise comportamental do mercado é uma das características básica dessa análise (PINHEIRO, 2009).

\section{METODOLOGIA}

Para este trabalho será feita uma pesquisa de objetivos gerais, explicativa e com base em documentos (GIL, 2002; VERGARA, 2005). Esta pesquisa comtemplará três fases: coleta, manipulação e análise dos dados. A coleta se dará a partir das demonstrações financeiras (Balanço Patrimonial e Demonstrativo de Resultados) das empresas, disponíveis no sítio eletrônico da BM\&F BOVESPA. Uma vez coletados, estes dados serão manipulados através de equações matemáticas, anteriormente conceituadas, e darão origem aos indicadores econômicos enunciados. Posteriormente estes indicadores econômicos serão correlacionados com o indicador financeiro lucratividade através do uso do programa Microsoft Excel online. 


\section{Revista \\ UNEMAT de \\ Contabilidade}

v. 9, n. 17,2020

A Regressão Linear fornecerá subsídios para analisar se estes indicadores econômicos têm alguma relação entre eles. A Correlação Linear nos fornecerá, através do Coeficiente de Pearson qual o grau desta correlação.

Conforme Bruni (2011, p. 266), “a análise de regressão e correlação tem como objetivo estimar numericamente o grau de relação que possa ser identificado entre populações de duas ou mais variáveis, a partir da determinação obtida com base em amostras selecionadas destas populações focalizadas" A regressão e a correlação possibilitam comprovar, de maneira empírica, se é adequada a afirmação que há relação entre as populações de duas ou mais variáveis.

O Coeficiente de Correlação de Pearson é o número que traduz a medida numérica que expressa o grau de relação encontrada através da correlação. Ele é obtido através da análise de duas ou mais variáveis, e determina qual seu grau de relação e se essas variáveis são de fato importantes ou relevantes a ponto de serem consideradas em um estudo. O Coeficiente de Pearson é uma medida do grau de relação linear entre duas variáveis quantitativas. Seu valor varia entre -1 a 1 , e pode ser expresso pela letra $r$. Segundo Callegari-Jacques (2003), o coeficiente de correlação pode ser avaliado qualitativamente da seguinte forma:

a. se $0,00<r<0,30$, existe fraca correlação linear;

b. se $0,30 \leq r<0,60$, existe moderada correlação linear;

c. se $0,60 \leq r<0,90$, existe forte correlação linear;

d. se $0,90 \leq r<1,00$, existe correlação linear muito forte.

$\mathrm{O}$ universo da pesquisa tem por base as quatro empresas listadas no índice IBOVESPA da Bolsa de Valores de São Paulo, participantes do segmento de consumo cíclico-vestuário e calçados e que utilizam o sistema de governança corporativa Novo Mercado. Este universo é composto pelas empresas Lojas Renner SA (Lojas Renner), Marisa Lojas SA (Lojas Marisa), Arezzo Indústria e Comércio SA (Arezzo) e Restoque Comércio e Confecção de Roupas SA (Le Lis Blanc). As amostras tem origem do balanço patrimonial e do demonstrativo de resultados referente aos anos de 2010 a 2014.

Os indicadores financeiros chamados de variáveis independentes, objeto deste estudo e correlacionados com o indicador financeiro lucratividade, variável dependente tem origem no balanço patrimonial e no demonstrativo de resultados conforme Quadro 1:

Quadro 1 - Fórmulas Financeiras. 


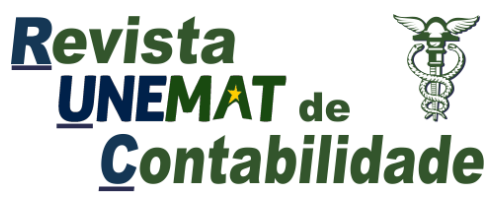

v. 9, ก. 17,2020

\begin{tabular}{|c|c|c|}
\hline FÓRMULAS FINANCEIRAS & INDICADOR ORIGINADO & $\begin{array}{c}\text { RELATÓRIO DE } \\
\text { ORIGEM }\end{array}$ \\
\hline$\frac{\text { LucroLiquido }}{\text { ReceitaOperacionalLiquida }}$ & Lucratividade & DRE \\
\hline$\frac{\text { AtivoCirculante }}{\text { PassivoCirculante }}$ & Liquidez Corrente & Balanço Patrimonial \\
\hline$\frac{\text { CustoMercadoriaVendida }}{\text { Estoque }}$ & Giro do Estoque & DRE/Balanço Patrimonial \\
\hline$\frac{\text { PassivoTotal }}{\text { AtivoTotal }}$ & Índice de Endividamento Geral & Balanço Patrimonial \\
\hline AtivoTotal & Tamanho da Empresa & Balanço Patrimonial \\
\hline ReceitaOperacionalBruta & Tamanho da Empresa & DRE \\
\hline
\end{tabular}

Fonte: Elaborado pelo autor. Nota: Compilação dos autores.

Lucratividade é o resultado positivo do negócio após diminuir os custos e as despesas. Gitman (2010) divide a lucratividade em três tipos: margem de lucro bruto, margem de lucro operacional e margem de lucro líquido. A margem de lucro bruto é a que mede a porcentagem de cada unidade monetária (Real, no caso do Brasil) de vendas que permanece após a empresa deduzir o valor (custo) dos bens vendidos. Para isso, toma-se o lucro bruto, divide-se pela receita operacional líquida (ROL) (Equação 1).

MargemBruta $=\frac{\text { LucroBruto }}{\text { ReceitaOperacionalLiquida }}$

Margem de lucro operacional é aquela apurada após deduzir da venda as despesas e os custos, exceto juros, imposto de renda e dividendos de ações preferenciais. Para obtenção do lucro operacional, utiliza-se o lucro bruto e subtraem-se todas as despesas, exceto juros, imposto de renda e dividendos (Equação 2).

MargemdeLucroOperacional $=\frac{\text { Lucrooperacional }}{\text { ReceitaOperacionalLiquida }}$

A margem de lucro líquido é a que mede a porcentagem de cada unidade monetária de vendas remanescente após a dedução de todos os custos e despesas. Para calcular a margem líquida, divide-se o lucro líquido pela receita operacional líquida (Equação 3). 
Margemlíquida $=\frac{\text { Lucroliquido }}{\text { Receitaoperacionallíquida }} \times 100$.

Para este trabalho será utilizada a margem de lucro líquido. Segundo Gitman (2010), é frequentemente associada ao sucesso de uma empresa em relação ao lucro obtido com vendas.

Conforme este autor, liquidez é a capacidade de uma empresa de saldar suas obrigações de curto prazo à medida que vencem. Para Hoji (2010), a liquidez mostra a situação financeira da empresa, e, quanto maior for esse índice, melhor. Os quatro indicadores de liquidez são: corrente, seca, imediata e geral.

A liquidez corrente (Equação 4) é aquela obtida a partir da divisão do ativo circulante pelo passivo circulante.

Liquidezcorrente $=\frac{\text { Ativocirculante }}{\text { Passivocirculante }}$

A liquidez seca (Equação 5), cujo cálculo se assemelha ao da liquidez corrente, mas exclui da fórmula o estoque, que costuma ser o menos líquido dos ativos circulantes. Então para cálculo da liquidez seca diminuímos do ativo circulante os estoques e dividimos pelo passivo circulante.

Liquidezseca $=\frac{\text { Ativocirculante-Estoques }}{\text { Passivocirculante }}$

A liquidez imediata (Equação 6), é calculada a partir da divisão da disponibilidade de caixa pelo passivo circulante.

Liquidezimediata $=\frac{\text { Disponibilidade }}{\text { Passivocirculante }}$

Liquidez geral (Equação 7) é aquela que resulta da soma do ativo circulante e ativo realizável no longo prazo, dividido pela soma do passivo circulante com o passivo não circulante.

Liquidezgeral $=\frac{\text { Ativo }+ \text { Ativoreal.longoprazo }}{\text { Passivo }+ \text { Passivonão。 }}$ 


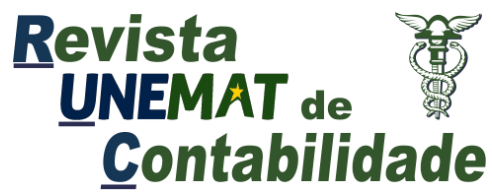

v. 9, n. 17,2020

Para este trabalho será utilizada a liquidez corrente, pois ela dá uma dimensão mais clara da disponibilidade de caixa no curto prazo, ou seja, dentro do ano corrente.

"Os índices de atividade medem a velocidade com que diversas contas se convertem em vendas ou caixa-entradas e saídas" (GITMAN, 2010, p. 51). Sua análise fornece informações sobre aspectos da gestão da empresa, como política de estoques, financiamento de compras e financiamento de clientes (Hoji, 2010). São quatro esses índices: giro do estoque, prazo médio de recebimento, prazo médio de pagamento e giro do ativo total.

O giro de estoque (Equação 8) mede a liquidez do estoque da empresa, e é calculado a partir da divisão do custo das mercadorias vendidas pelo estoque.

Girodoestoque $=\frac{\text { Custodasmercvendidas }}{\text { Estoque }}$

O prazo médio de recebimento é a idade média das contas a receber e pode ser calculado a partir da divisão das contas a receber de clientes pela média diária de vendas (Equação 9).

Prazomédioderecebimento $=\frac{\text { Contasareceberdeclientes }}{\text { Médiadiáriadasvendas }}$

A Equação 10 é o prazo médio de pagamento, calculado pela divisão das contas a pagar a fornecedores pela média diária de compras.

Prazomédiodepagamento $=\frac{\text { Fornecedores }}{\text { Médiadiáriadecompras }}$

O giro do ativo total, que indica a eficiência com que a empresa usa seus ativos para gerar vendas, é obtido da divisão das vendas pelo ativo total (Equação 11).

Girodoativototal $=\frac{\text { Vendas }}{\text { Ativototal }}$

Para este trabalho, será utilizado o índice de atividade giro do estoque, que influencia os outros três indicadores e pode ser usado na formulação de políticas de prazo de pagamento a fornecedores e de vendas a clientes. 


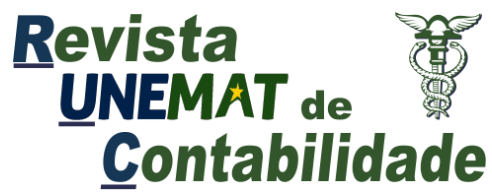

v. 9, n. 17,2020

O grau de endividamento mede o quanto de capital de terceiros a empresa está utilizando em relação a outros valores significativos do balanço patrimonial. Uma medida importante é o índice de endividamento geral, que mede a proporção do ativo total financiada pelos credores da empresa (Equação 12).

Índicedeendividamentogeral $=\frac{\text { Passivototal }}{\text { Ativototal }}$

O tamanho de uma empresa pode ser medido, segundo Fontana (2011), pelo seu total de ativos, que é a soma de todos os bens e direitos, inclusive os intangíveis como a marca. Para Lumbieri (2012), considera-se, para isso, o ativo total contábil.

Também podemos medir o tamanho de uma empresa pelo total das suas vendas (FONTANA, 2011). O faturamento líquido (total das vendas já descontados os impostos) é tudo o que a empresa fatura dentro de um período de tempo pré-estabelecido como o ano contábil, por exemplo.

Para fazer a comparação dos dados coletados, será utilizado o programa Microsoft Excel, versão online de 2010, e o software R Studio, para cálculo da correlação e significância estatística, que é medida pelo p-value.

\section{ANÁLISE E DISCUSSÃO DOS RESULTADOS}

\subsection{Análise Individual das Empresas}

\subsubsection{Lojas Renner S/A}

A seguir, o Quadro 2 contém o cálculo dos indicadores financeiros extraídos dos dados do Balanço Patrimonial e do Demonstrativo de Resultados dos Exercícios de 2010 a 2014 das Lojas Renner S/A. A lucratividade apresenta linha de tendência de queda no período visto. De 11,20\% em 2010 para 9,03\% em 2014.

Quadro 2 - Indicadores Lojas Renner S/A

\begin{tabular}{|c|c|c|c|c|c|c|}
\hline Ano & Lucratividade & $\begin{array}{c}\text { Liquidez } \\
\text { Corrente }\end{array}$ & $\begin{array}{c}\text { Giro do } \\
\text { Estoque }\end{array}$ & $\begin{array}{c}\text { Índice de } \\
\text { Endividamento }\end{array}$ & $\begin{array}{c}\text { Ativo } \\
\text { Total }\end{array}$ & Faturamento \\
\hline 2010 & 11,20 & 1,9159 & 4,2948 & 0,5842 & 2.456 .015 & 2.751 .338 \\
\hline
\end{tabular}




\begin{tabular}{|c|c|c|c|c|c|c|}
\hline 2011 & 10,40 & 1,9196 & 3,4980 & 0,6129 & 2.983 .504 & 3.238 .543 \\
\hline 2012 & 9,20 & 1,4473 & 3,5603 & 0,6537 & 3.770 .028 & 3.862 .508 \\
\hline 2013 & 9,32 & 1,5530 & 3,6506 & 0,6693 & 4.515 .524 & 4.370 .946 \\
\hline 2014 & 9,03 & 1,7177 & 3.5001 & 0,6513 & 5.321 .840 & 5.216 .820 \\
\hline
\end{tabular}

Fonte: BOVESPA (2015). Nota: Dados trabalhados pelo autor. Valores em R \$1000.

Conforme os dados retirados do Quadro 2, a liquidez corrente apresenta queda no período analisado, pois parte em 2010 de 1,91 e termina 2014 em 1,71, embora tenha se recuperado nos dois últimos anos do período. Para cada $\mathrm{R} \$ 1,00$ que a empresa devia, possuía $\mathrm{R} \$ 1,72$ para quitá-lo em 31.12.2014. O indicador financeiro de giro de estoque apresenta queda. Em 2010 era de 4,29, e encerrou 2014 em 3,50. Já o índice de endividamento geral mostrou pequeno acréscimo no período. De 0,58 para 0,65 do início ao final do mesmo. Um pequeno acréscimo de $11,48 \%$ no indicador. O Ativo Total, um dos indicadores usados para se medir o tamanho da empresa teve crescimento médio anual de mais de $21 \%$ ao longo do período sob análise. O outro indicador financeiro usado para aferir o tamanho da empresa é o faturamento que cresceu à taxa média de $17 \%$ anuais.

Tabela 1 - Correlação da lucratividade com os demais índices no período de 2010 a 2014

\begin{tabular}{c|c|c|c|c|c}
\hline Coeficientes & $\begin{array}{c}\text { Liquidez } \\
\text { Corrente }\end{array}$ & $\begin{array}{c}\text { Giro do } \\
\text { Estoque }\end{array}$ & $\begin{array}{c}\text { Índice de } \\
\text { Endividamento }\end{array}$ & Ativo Total & Faturamento \\
\hline $\mathrm{R}$ & 0,80893 & 0,76912 & $-0,95551$ & $-0,89800$ & $-0,89277$ \\
\hline $\mathrm{p}$-value & 0,09835 & 0,1279 & 0,01139 & 0,03816 & 0,04104 \\
\hline
\end{tabular}

Fonte: Elaborado pelos autores com base na saída do programa R Studio (2019).

Dos indicadores financeiros analisados, todos têm forte correlação linear com a lucratividade, pois quanto mais próximo a 1, mais fortemente estão correlacionados os dados. Os indicadores de liquidez corrente e giro do estoque tem forte correlação linear positiva; diminuem à medida que diminui a lucratividade. Os indicadores de índice de endividamento geral e tamanho da empresa, tanto pelo faturamento líquido, quanto pelo ativo total tem correlação muito forte e negativa. Enquanto o percentual de lucratividade cai, estes aumentam em uma proporção muito parecida.

O valor da significância é representado pelo p-value. Para este estudo, devido a quantidade limitada de dados obtidos, considerou-se um p-value desejável inferior a 0,1 , para assim o coeficiente encontrado ter significância estatística. Portanto, apenas o giro do estoque 


\section{Revista \\ UNEMAT de \\ Contabilidade}

v. 9, n. 17,2020

não apresentou significância, o que pode ser justificado pela quantidade de dados coletados de apenas 5 períodos. Os demais coeficientes apresentaram significância aceitável, abaixo de 0,1.

Nas Lojas Renner S/A o destaque de indicador que mais se correlaciona com o indicador de lucratividade é o índice de endividamento geral. Neste, a correlação é muito forte e negativa de $-0,95551$. A correlação negativa indica que quando um indicador apresentar crescimento, o outro indicador irá apresentar queda, mantendo uma relação inversa. Enquanto a lucratividade cai, o indicador de endividamento geral cresce, sendo inversamente proporcionais em $-0,95551$ de um total de $-1,0$.

\subsubsection{Marisa Lojas S/A}

A seguir, a Quadro 3 contém o cálculo dos indicadores financeiros extraídos dos dados do Balanço Patrimonial e do Demonstrativo de Resultados dos Exercícios de 2010 a 2014 da Marisa Lojas S/A. A lucratividade apresenta linha de tendência de forte queda; varia de $10,05 \%$ em 2010 para $1,52 \%$ em 2014.

\begin{tabular}{|c|c|c|c|c|c|c|}
\hline Ano & Lucratividade & $\begin{array}{c}\text { Liquidez } \\
\text { Corrente }\end{array}$ & Giro do Estoque & $\begin{array}{c}\text { Índice de } \\
\text { Endividamento }\end{array}$ & $\begin{array}{c}\text { Tamanho } \\
\text { do Ativo }\end{array}$ & Faturamento \\
\hline 2010 & 10,05 & 1,4936 & 4,4803 & 0,6007 & 2.061 .292 & 2.075 .683 \\
\hline 2011 & 7.24 & 2,3040 & 4,4251 & 0,6474 & 2.432 .599 & 2.450 .315 \\
\hline 2012 & 7,99 & 2,7767 & 3,9930 & 0,5743 & 2.440 .691 & 2.877 .388 \\
\hline 2013 & 2,70 & 2,4580 & 4,8486 & 0,5636 & 2.573 .671 & 3.096 .990 \\
\hline 2014 & 1,52 & 2,1276 & 4,7731 & 0,6106 & 2.968 .588 & 3.344 .593 \\
\hline
\end{tabular}

Fonte: BOVESPA (2015). Nota: Dados trabalhados pelo autor. Valores em $\mathrm{R} \$ 1000$.

De acordo com os dados do Quadro 3, a liquidez corrente possui variação ao longo do período, mas fechou positiva. Subiu de 1,49 para 2,12 no período, embora tenha apresentado variações ao longo do mesmo. O giro de estoque apresentou pequena variação positiva ao longo do período. Oscilou, passou de 4,48 em 2010 para 4,77 em 2014. Segundo Hoji (2010) esse resultado significa que a empresa gira seu estoque 4,77 vezes por ano, ou seja, a cada 76 dias. Já o índice de endividamento geral, que mede a proporção dos ativos da empresa financiados pelos credores desta (GITMAN, 2010), manteve-se estável. O Ativo Total 


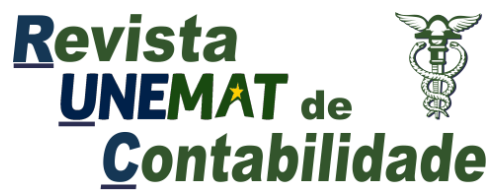

v. 9, n. 17,2020

cresceu, na média, em torno $10 \%$ ao ano no período. Usado como uma das medidas do tamanho da empresa, o faturamento cresceu no período à taxa média anual de $12 \%$.

Tabela 2 - Correlação da lucratividade com os demais índices no período de 2010 a 2014

\begin{tabular}{c|c|c|c|c|c}
\hline Coeficientes & $\begin{array}{c}\text { Liquidez } \\
\text { Corrente }\end{array}$ & $\begin{array}{c}\text { Giro do } \\
\text { Estoque }\end{array}$ & $\begin{array}{c}\text { Índice de } \\
\text { Endividamento }\end{array}$ & Ativo Total & Faturamento \\
\hline $\mathrm{r}$ & $-0,30200$ & $-0,72000$ & 0,1728 & $-0,91425$ & $-0,90090$ \\
\hline $\mathrm{p}$-value & 0,6209 & 0,1687 & 0,7811 & 0,03089 & 0,03728 \\
\hline
\end{tabular}

Fonte: Elaborado pelos autores com base na saída do programa R Studio (2019).

Conforme a Tabela 2, feita a correlação dos indicadores financeiros propostos com o índice de lucratividade, demonstrou-se que existe baixa correlação desta com a liquidez e com o índice de endividamento geral ela é ainda menor. Existe uma forte correlação com o índice de giro do estoque, o qual apresentou variação positiva gerando, então, uma correlação linear negativa, eis que variam em sentidos opostos, enquanto um cresce o outro cai.

Existe correlação muito forte da lucratividade com a variação do tamanho da empresa, nos dois indicadores usados para medi-la, com destaque para o indicador de variação do ativo. Com o indicador de lucratividade em baixa e os indicadores de tamanho da empresa crescendo, a correlação linear torna-se negativa, de $-0,91425$ no caso de medida pelo Ativo Total que, na Marisa Lojas S/A é o indicador financeiro que mais se correlaciona com o indicador de lucratividade. Neste índice, obtivemos significância estatística, com um p-value de 0,03089 , inferior a 0,1 , validando o coeficiente encontrado.

\subsubsection{Arezzo Indústria e Comércio S/A}

A Arezzo Ind e Com S/A cresceu $16 \%$ em faturamento e acima de $31 \%$ no ativo total durante o período analisado. Apresentou pequenas variações no indicador de lucratividade ao longo do período sob análise, com pequena queda de 5,44\% (de 11,29\% para 10,70\%).

Quadro 4 - Indicadores Arezzo Ind e Com S/A

\begin{tabular}{|c|c|c|c|c|c|c|}
\hline Ano & Lucratividade & $\begin{array}{l}\text { Liquidez } \\
\text { Corrente }\end{array}$ & $\begin{array}{c}\text { Giro de } \\
\text { Estoque }\end{array}$ & $\begin{array}{c}\text { Índice de } \\
\text { Endividamento }\end{array}$ & $\begin{array}{c}\text { Tamanho } \\
\text { do Ativo }\end{array}$ & Faturamento \\
\hline 2010 & 11,29 & 2,2292 & 6,9560 & 0,4547 & 268.156 & 571.525 \\
\hline 2011 & 13.49 & 4,2258 & 6,9267 & 0,2479 & 510.628 & 678.907 \\
\hline
\end{tabular}




\begin{tabular}{|l|c|c|c|c|c|c|}
\hline 2012 & 11,26 & 4,0305 & 6,3643 & 0,2870 & 636.591 & 860.335 \\
\hline 2013 & 11,48 & 3,8447 & 6,3122 & 0,2690 & 703.866 & 962.950 \\
\hline 2014 & 10,70 & 3,4600 & 6,1511 & 0,2765 & 796.509 & 1.052 .909 \\
\hline
\end{tabular}

Fonte: BOVESPA (2015). Nota: Dados trabalhados pelo autor. Valores em R $\$ 1000$.

O indicador financeiro de liquidez iniciou em 2,22 em 2010, subiu nos dois anos subsequentes e caiu um pouco e estabilizou-se na casa dos 3,46. O indicador de giro do estoque também destoa das demais empresas analisadas, ficando muito acima da média, ou seja, acima de 6,1. O índice de endividamento geral também é muito favorável, já que está em um patamar extremamente baixo, tendo inclusive caído nesse período. O índice apresentou queda de 0,45 para 0,27. Segundo Gitman (2010), significa dizer que a empresa possui o Ativo Total quase quatro vezes maior que o Passivo Total. Os indicadores de tamanho da empresa mostram também um crescimento consistente e gradativo. O Ativo Total cresceu na ordem de $16 \%$ médios anuais. O Faturamento cresceu mais de $31 \%$ médio anual.

Tabela 3 - Correlação da lucratividade com os demais índices no período de 2010 a 2014

\begin{tabular}{c|c|c|c|c|c}
\hline Coeficientes & $\begin{array}{c}\text { Liquidez } \\
\text { Corrente }\end{array}$ & $\begin{array}{c}\text { Giro do } \\
\text { Estoque }\end{array}$ & $\begin{array}{c}\text { Índice de } \\
\text { Endividamento }\end{array}$ & Ativo Total & Faturamento \\
\hline $\mathrm{R}$ & 0,459930 & 0,649155 & $-0,33123$ & $-0,29972$ & $-0,50512$ \\
\hline $\mathrm{p}$-value & 0.4359 & 0.2359 & 0.5873 & 0.6226 & 0.3841 \\
\hline
\end{tabular}

Fonte: Elaborado pelos autores com base na saída do programa R Studio (2019).

Com a empresa em crescimento forte e o indicador de lucratividade em pequena queda, o indicador financeiro que mais se correlacionou com o indicador de lucratividade foi o de giro do estoque que, apesar de alto, teve, como a lucratividade, uma pequena queda no período, ficando essa correlação linear positiva de 0,865261 . Porém, esta correlação não atingiu significância estatística, com um p-value de 0,2359 , o que pode ser atribuído à quantidade de elementos amostrais insuficientes.

\subsubsection{Restoque Comércio e Confecções de Roupas S/A (Le Lis Blanc)}




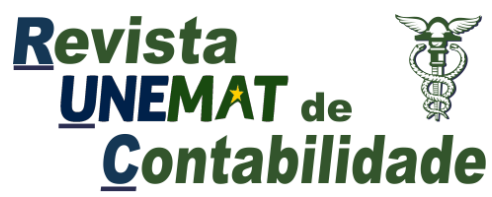

v. 9, n. 17,2020

A última empresa sob análise possui, como as demais, crescimento sustentado ao longo do período da análise (21,52\% no faturamento e $87,25 \%$ no ativo total, médios anuais). Nesse cenário, o indicador de lucratividade cai vertiginosamente, de 10,55\% em 2010 para 0,58 em 2014, apresentando resultado negativo no final do período, conforme Quadro 5.

Quadro 5 - Indicadores Restoque S/A

\begin{tabular}{|c|c|c|c|c|c|c|}
\hline Ano & Lucratividade & $\begin{array}{c}\text { Liquidez } \\
\text { Corrente }\end{array}$ & $\begin{array}{c}\text { Giro do } \\
\text { Estoque }\end{array}$ & $\begin{array}{c}\text { Índice de } \\
\text { Endividamento }\end{array}$ & $\begin{array}{c}\text { Ativo } \\
\text { Total }\end{array}$ & Faturamento \\
\hline 2010 & 10,55 & 2,7104 & 1,6865 & 0,4438 & 275.069 & 351.091 \\
\hline 2011 & 7.99 & 2,1073 & 1,3897 & 0,6371 & 542.893 & 471.100 \\
\hline 2012 & 1,83 & 1,9469 & 1,0205 & 0,7862 & 973.059 & 635.914 \\
\hline 2013 & $-0,02$ & 1,9120 & 1,4205 & 0,8422 & 989.623 & 713.678 \\
\hline 2014 & $-0,58$ & 1,2918 & 0,8659 & 0,4666 & 3.381 .678 & 765.717 \\
\hline
\end{tabular}

Fonte: BOVESPA (2015). Nota: Dados trabalhados pelo autor. Valores em R $\$ 1000$.

Conforme o Quadro 5, o indicador de liquidez mostra uma expressiva queda durante o intervalo de tempo analisado. Caiu 52,45\% entre 2010 e 2014. Mantendo a mesma tendência registrada pelo indicador de Liquidez Corrente, o Giro do Estoque também caiu durante o período: de 1,68 para 0,86, ou seja, uma queda de 48,70\%. O indicador de endividamento geral inicia e termina o período no mesmo patamar, embora uma variação para cima durante o período. Os indicadores de tamanho da empresa mostram tendência de forte alta. O Ativo Total passou de $\mathrm{R} \$ 275.069,00$ para $\mathrm{R} \$ 3.381 .678,00$ (Em $\mathrm{R} \$ 1.000)$. O indicador de Faturamento cresceu a uma taxa média de $21,52 \%$ anuais no período.

Tabela 4 - Correlação da lucratividade com os demais índices no período de 2010 a 2014

\begin{tabular}{c|l|l|l|l|l}
\hline Coeficientes & \multicolumn{1}{|c|}{$\begin{array}{c}\text { Liquidez } \\
\text { Corrente }\end{array}$} & $\begin{array}{c}\text { Giro do } \\
\text { Estoque }\end{array}$ & $\begin{array}{c}\text { Índice de } \\
\text { Endividamento }\end{array}$ & Ativo Total & Faturamento \\
\hline $\mathrm{r}$ & 0,864300 & 0,754093 & $-0,450394$ & $-0,697098$ & $-0,992425$ \\
\hline $\mathrm{p}$-value & 0,05877 & 0,1409 & 0,4466 & 0,1908 & 0,0007904 \\
\hline
\end{tabular}

Fonte: Elaborado pelos autores com base na saída do programa R Studio (2019).

A Restoque teve, ao longo do período analisado, um forte crescimento no tamanho do seu Ativo Total. Esse fato deve-se a um aumento exponencial na conta Intangível, resultado da agregação de uma marca pela empresa. 


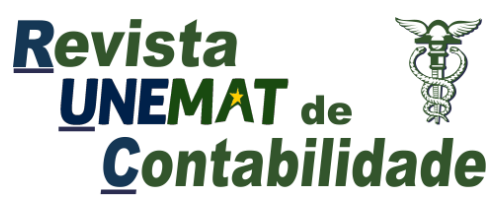

v. 9, n. 17,2020

O indicador que mais se correlaciona com o indicador de lucratividade é o de tamanho da empresa medido pelo faturamento líquido. Como variaram em direções opostas, com a lucratividade em baixa e o faturamento em alta, são inversamente proporcionais, ou seja, a correlação linear é negativa de -0,992425, com significância estatística.

\subsection{Análise e Discussão dos Resultados das Empresas}

Ao longo dos últimos 5 anos fiscais, de 2010 a 2014, foram correlacionados esses indicadores com o indicador de lucratividade no intuito de se encontrar relação entre um ou mais indicadores financeiros e a lucratividade dessas empresas. Analisadas individualmente, as quatro empresas apresentaram resultados distintos.

Quadro 6 - Correlação entre o Indicador de Lucratividade e:

\begin{tabular}{|c|c|c|c|c|c|}
\hline Empresas & Liquidez & Giro Estoque & $\begin{array}{c}\text { Índice } \\
\text { Endividamento }\end{array}$ & Ativo Total & Faturamento \\
\hline $\begin{array}{c}\text { Lojas Renner } \\
\text { S/A }\end{array}$ & 0,80893 & 0,76912 & $-0,95551$ & $-0,89800$ & $-0,89277$ \\
\hline $\begin{array}{c}\text { Marisa Lojas } \\
\text { S/A }\end{array}$ & $-0,30200$ & $-0,72000$ & 0,1728 & $-0,91425$ & $-0,90090$ \\
\hline Arezzo S/A & 0,45993 & 0,649155 & $-0,33123$ & $-0,29972$ & $-0,50512$ \\
\hline Restoque S/A & 0,864300 & 0,754093 & $-0,450394$ & $-0,697098$ & $-0,992425$ \\
\hline
\end{tabular}

Fonte: BOVESPA (2015). Nota: Dados trabalhados pelo autor.

Nas Lojas Renner S/A o indicador de lucratividade possui correlação forte com todos os indicadores analisados. Assim, verifica-se que a lucratividade tem forte relação com os indicadores de liquidez, giro de estoque, índice de endividamento, ativo total e faturamento. Com a lucratividade em queda, dois outros indicadores, o indicador de liquidez corrente e o de giro do estoque que também caem ao longo do período em análise, a correlação linear é positiva.

O indicador de endividamento geral cresce (também piora seu desempenho), mas como oscila na direção oposta, sua correlação com a lucratividade é linear negativa. Esta correlação é muito forte e é o indicador que mais intimamente se correlaciona com o indicador de lucratividade. Os dois indicadores que medem o tamanho da empresa, o ativo total e o faturamento crescem, ou seja, seu desempenho é positivo. Variam no sentido oposto ao da lucratividade. Por isso, sua correlação com esta é linear negativa. O que se depreende através desta análise, que se atém aos indicadores e ao tempo propostos é que, à medida que a 


\section{Revista \\ UNEMAT de \\ Contabilidade}

v. 9, n. 17,2020

empresa cresce, seu endividamento também cresce e diminuem a liquidez e a lucratividade e seu giro de estoque fica mais lento. Os motivos demandariam outro estudo.

Na Marisa Lojas S/A também o destaque foi o crescimento da empresa, captado pelos indicadores de ativo total e de faturamento. Com o indicador de lucratividade em forte queda, correlacionaram-se negativamente, exceto o índice de endividamento, que possui correlação positiva. Mas a sua correlação foi muito forte, com destaque para o indicador do ativo total. O índice de endividamento total correlacionou-se de forma quase nula e o de liquidez teve correlação muito fraca. O giro do estoque teve leve melhora, então, teve correlação negativa, visto que a lucratividade caiu. Nesta empresa, o que teve maior influência sobre o indicador de lucratividade foi o crescimento da empresa.

$\mathrm{Na}$ Arezzo Indústria e Comércio S/A, exceção nas empresas analisadas, o crescimento da empresa não foi determinante na redução da lucratividade. Deve ser considerado nesta análise que, das empresas citadas, esta foi a que teve menor redução no indicador de lucratividade no período. Nesta empresa, o giro do estoque, que também caiu no período é o indicador que mais se correlaciona com o indicador de lucratividade.

A Restoque Comércio e Confecção de Roupas S/A foi a única das empresas que deu prejuízo no período. Seu indicador de lucratividade ficou negativo nos dois últimos anos da análise. O indicador de liquidez caiu (piorou) e o estoque girou mais devagar, fato que diminui a margem de lucro. Das empresas analisadas, é a única em que o giro do estoque é inferior a 1,0. Ou seja, girou menos que uma vez no ano de 2014. Ainda assim, teve crescimento nos indicadores de tamanho da empresa. $\mathrm{O}$ indicador financeiro de tamanho da empresa medido pelo faturamento se destacou na análise de correlação, sendo o que possui a maior intimidade com a lucratividade, apresentando uma relação positiva com coeficiente considerado muito forte.

\section{CONSIDERAÇÕES FINAIS}

Este trabalho procurou identificar quais os indicadores financeiros nas empresas analisadas mais se correlacionam com o indicador de lucratividade em um período de tempo pré-estabelecido. Em comum, estas empresas tem um crescimento elevado no tamanho da empresa, medido pelos indicadores de Ativo Total e de Faturamento, com queda no indicador de lucratividade. Análise da correlação linear dos indicadores financeiros propostos com o indicador de lucratividade faz supor que o crescimento acelerado das empresas afeta 


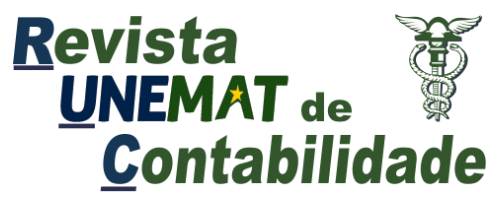

v. 9, n. 17,2020

diretamente sua margem de lucratividade, exceção feita à Arezzo, embora o indicador de crescimento medido pelo faturamento tenha tido uma correlação fraca com o de lucratividade (CALLEGARI-JACQUES, 2003).

Outro indicador que teve forte correlação com o indicador de lucratividade em todas as empresas foi o de giro do estoque. A rapidez com que a empresa vende seus produtos tende a afetar diretamente na sua lucratividade. Em todas as empresas analisadas, quando caiu o índice de giro do estoque, também caiu o percentual de lucratividade, com exceção da Marisa Lojas S/A, que também teve forte correlação nestes indicadores, mas negativa. Os motivos desta correlação ser negativa também demandaria outro estudo, pois não está no escopo deste trabalho de análise. Pode tratar-se, inclusive, de política interna da empresa para ganhar mercado, diminuindo sua margem, visto que esta caiu suavemente ao longo do período.

Por fim, pode-se dizer que, quando um fator afeta três entre quatro empresas analisadas, é forte a tendência de que ele deve ser considerado como fato. Então, ao serem postas em uma análise conjunta, descontadas as peculiaridades de cada uma e atendo-se somente aos dados, empresas e período aqui analisados, pode-se afirmar que os indicadores que mais influenciam o indicador de lucratividade- são os indicadores de giro do estoque e de tamanho da empresa, medidos pelo ativo total e, sobretudo pelo faturamento.

Sugere-se, para futuras pesquisas, aplicar a técnica estatística de regressão linear, uma vez que nesta pesquisa utilizou-se apenas a correlação linear. Também se sugere a ampliação do prazo estudado, que no caso deste artigo foi de 5 anos, aumentando assim a amostragem dos dados, o que permite análises mais precisas.

\section{REFERÊNCIAS BIBLIOGRÁFICAS}

BRUNI, A. L. Estatística aplicada à gestão empresarial. $3^{\text {a }}$ edição. São Paulo: Atlas, 2011.

CALLEGARI-JACQUES, S. M. Bioestatística: princípios e aplicações. $1^{\text {a }}$ edição. Porto Alegre: Artmed, 2003.

ELDER, A. Como se transformar em um operador e investidor de sucesso. 18. ed. Rio de Janeiro: Alta Books, 2017.

FONTANA, F. B. Fatores explicativos do nível de evidenciação voluntária de informações sobre recursos intangíveis das empresas listadas na BM\&FBOVESPA. Dissertação (Mestrado em Ciências Contábeis) - Universidade do Vale do Rio dos Sinos, São Leopoldo, 2011. 


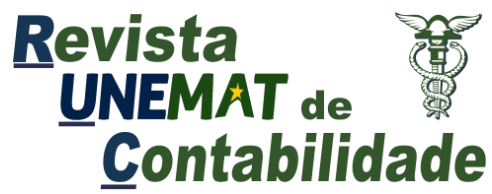

v. 9, n. 17,2020

GARCIA, P. Porque bolsa de valores não é cassino. 2017. Disponível em:

<https://tinyurl.com/y6srkyg7>. Acesso em: 19/05/2019.

GIL, A. C. Como elaborar projetos de pesquisa. $4^{\text {a }}$ edição. São Paulo: Atlas, 2002.

GITMAN, L. J. Princípios da administração financeira. 12ª edição. São Paulo: Pearson Prentice Hall, 2010.

GOLDEMBERG, M. Por que a moda importa tanto? O Estado de São Paulo, São Paulo, p. J3, 22 jan. 2006.

HOJI, M. Administração financeira e orçamentária: matemática financeira aplicada, estratégias financeiras, orçamento empresarial. $9^{a}$ edição. São Paulo: Atlas, 2010.

Lista das empresas na BM\&FBOVESPA (consulta da disponibilidade de demonstrações financeiras e dados). Disponível em:

http://www.bmfbovespa.com.br/Cias-Listadas/Empresas-

Listadas/BuscaEmpresaListada.aspx?idioma=pt-br Acesso em: 15 out. 2015.

LUMBIERI, L. Nível de evidenciação de informações sobre o capital humano e a percepção de valor das empresas da BM\&FBOVESPA. Dissertação (Mestrado em Ciências Contábeis) - Universidade do Vale do Rio dos Sinos, São Leopoldo, 2012.

MALLMANN, T. O Que São e Como Funcionam as Corretoras de Valores? 2017. Disponível em: <https://tinyurl.com/y2h9txfy>. Acesso em: 19/05/2019.

MARTINS, G. A. Estudo de caso: uma estratégia de pesquisa. $2^{a}$ edição. São Paulo: Atlas, 2008.

OLIVERIA, M. D. B. de. Introdução ao mercado de ações: o Que é. para Que Serve... 2. ed. Rio de Janeiro: Cnbv, 1980.

PINHEIRO, J. L. Mercado de capitais: fundamentos e técnicas. 6. ed. São Paulo: Atlas, 2009.

RECH, M;DENICOL,R;CASAGRANDE, J,D; ZANANDREA, G; CAMARGO, M, E; FABRIS,J,P; BIEGELMEYER, U. H. Credit Concession in the Brazilian Banking Sector in the Period of the International Financial Crisis.International Journal of Advanced Engineering Research and Science V 6 S 9, 2019.

VERGARA, S. C. Métodos de pesquisa em administração. São Paulo: Atlas, 2005. 